San Jose State University

SJSU ScholarWorks

Master's Theses

Master's Theses and Graduate Research

Spring 2018

\title{
An Interpretative Phenomenological Analysis of 2013 Boston Marathoners' Experience of Running a Subsequent Boston Marathon
}

Allison Grace

San Jose State University

Follow this and additional works at: https://scholarworks.sjsu.edu/etd_theses

\section{Recommended Citation}

Grace, Allison, "An Interpretative Phenomenological Analysis of 2013 Boston Marathoners' Experience of Running a Subsequent Boston Marathon" (2018). Master's Theses. 4903.

DOI: https://doi.org/10.31979/etd.gyb6-287p

https://scholarworks.sjsu.edu/etd_theses/4903

This Thesis is brought to you for free and open access by the Master's Theses and Graduate Research at SJSU ScholarWorks. It has been accepted for inclusion in Master's Theses by an authorized administrator of SJSU ScholarWorks. For more information, please contact scholarworks@sjsu.edu. 


\title{
AN INTERPRETATIVE PHENOMENOLOGICAL ANALYSIS OF 2013 BOSTON MARATHONERS' EXPERIENCE OF RUNNING A SUBSEQUENT BOSTON MARATHON
}

\author{
A Thesis \\ Presented to \\ The Faculty of the Department of Kinesiology \\ San José State University \\ In Partial Fulfillment \\ of the Requirements for the Degree \\ Master of Arts
}

by

Allison Grace

May 2018 
(C) 2018

Allison Grace

ALL RIGHTS RESERVED 
The Designated Thesis Committee Approves the Thesis Titled

AN INTERPRETATIVE PHENOMENOLOGICAL ANALYSIS OF 2013 BOSTON MARATHONERS' EXPERIENCE OF RUNNING A SUBSEQUENT BOSTON MARATHON

by

Allison Grace

APPROVED FOR THE DEPARTMENT OF KINESIOLOGY

SAN JOSÉ STATE UNVIERSITY

May 2018

Theodore M. Butryn, Ph.D.

Department of Kinesiology

Tamar Z. Semerjian, Ph.D.

Department of Kinesiology

Cole G. Armstrong, Ph.D.

Department of Kinesiology 


\title{
ABSTRACT \\ AN INTERPRETATIVE PHENOMENOLOGICAL ANALYSIS OF 2013 BOSTON MARATHONERS' EXPERIENCE OF RUNNING A SUBSEQUENT BOSTON MARATHON
}

\author{
by Allison Grace
}

While trauma experiences have been explored in several sport-related research studies, there is a lack of research on athletes' experiences of a terror attack in sport. The present study qualitatively explored the meanings that 2013 Boston Marathoners ascribed to their experience of returning to the Boston Marathon to compete. Eight participants took part in semi-structured interviews. Interviews were analyzed via interpretative phenomenological analysis. Eight themes emerged and were organized temporally around pre-2013 Boston Marathon experience, 2013 Boston Marathon experience, and post-2013 Boston Marathon experience. Results suggest participants initially had difficulty processing their 2013 experience, but ultimately, several participants had a changed perspective on the sport. Furthermore, results suggest that a return to the Boston Marathon provided an outlet for some participants to demonstrate their defiance to the attackers, display resilience, and achieve a goal that they could not in 2013. The results are discussed within the context of Emotional Processing Theory. 


\section{ACKNOWLEDGMENTS}

I would like to express my gratitude to the individuals who assisted me in making this thesis possible.

First, I would like to acknowledge my thesis committee chair, and graduate advisor, Dr. Ted Butryn. Dr. Butryn, thank you for your guidance, patience, and confidence in me throughout this project and during my graduate education at San José State University. Thank you for always making yourself available to listen to my ideas, questions, anxieties, and challenging me to be a better student and researcher. Additionally, I would like to express my gratitude to you and to San José State University for seeing my potential and for your confidence in my ability to succeed in this program. I am grateful to have had the opportunity to pursue my graduate education at this institution.

To Dr. Tamar Semerjian and Dr. Cole Armstrong, I would like to thank you both for being a part of my thesis committee. I am grateful for your expertise, guidance, feedback, and support throughout this process.

I would also like to express my sincere gratitude to the runners who volunteered to participate in this study. Thank you not only for your courage, but for your willingness and openness in sharing your experiences with me. I am honored and grateful that you chose to share these experiences with me. Without you, this thesis truly would not have been possible.

Mom and Dad, thank you not only for your confidence in my abilities to succeed in graduate school, but for your support and reassurance of my abilities to succeed at 
anything I have set out to accomplish. Thank you for all that you do.

And lastly, to my neighbors in San José who have become like a second family to me during my time here. Thank you for making San José - a place I moved to knowing no one - into a place where I have made lifelong friendships. 


\section{TABLE OF CONTENTS}

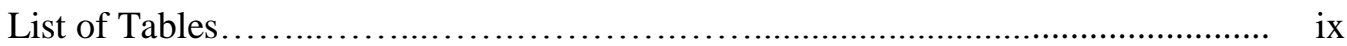

Chapter 1: Introduction........................................................ 1

Statement of Purpose........................................................ 8

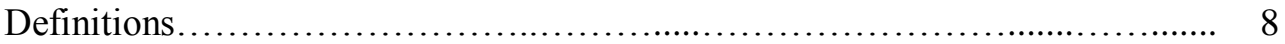

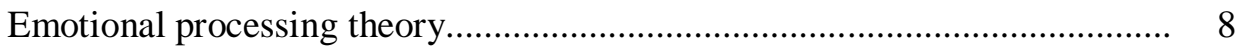

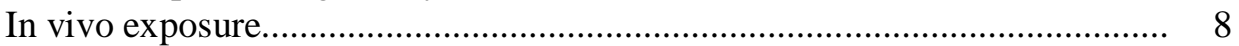

Interpretative phenomenological analysis............................................... 9

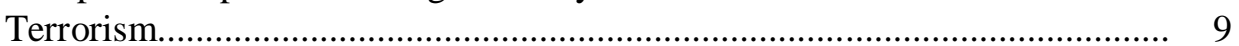

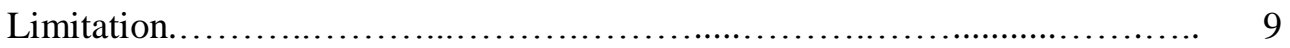

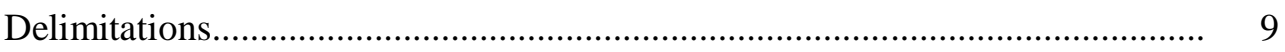

Chapter 2: Journal Article............................................................. 10

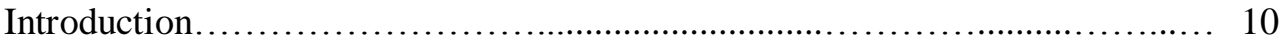

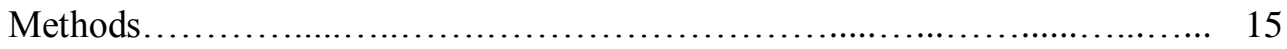

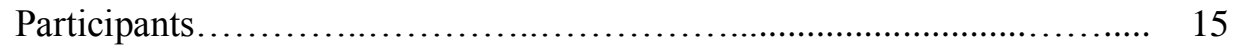

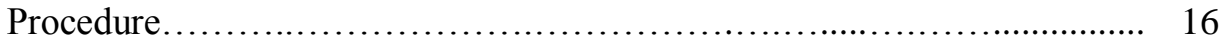

Bracketing Interview.................................................... 17

Interview Guide............................................................ 17

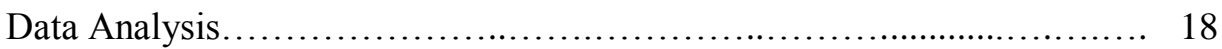

Academic Rigor........................................................ 19

Results and Discussion................................................ 20

Pre-2013 Boston Marathon.................................................. 20

Running Identity................................................. 20

2013 Boston Marathon............................................... 22

Boston Marathon as Unique Race Experience........................... 22

Participants' Experience of Gaining the Knowledge

There Had Been an Incident at the Finish Line.............................. 23

How Participants Made Sense of Their Trauma Experience................ 24

Identification with Other Terror Attacks............................... 25

Post-2013 Boston Marathon............................................... 27

Experiencing the Desire to Return to the Boston Marathon.................. 27

Safety and Security............................................................... 29

Altered Worldview.................................................................... 32

Conclusion and Directions for Future Research.............................. 34

Limitations.............................................................. 36

Directions for Future Research........................................ 36

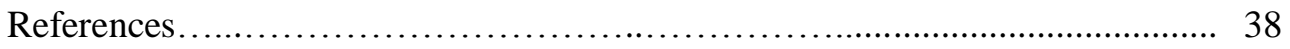

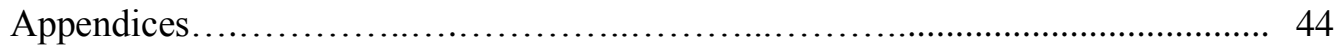

Appendix A: Demographic Questionnaire...................................... 44

Appendix B: Recruitment Notice............................................. 45

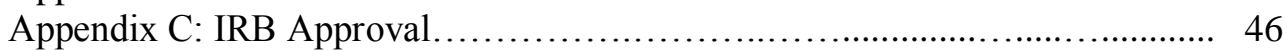

Appendix D: Informed Consent............................................... 47 
Appendix E: Interview Guide............................................. 49

Appendix F: Theme Table................................................. 50 


\section{LIST OF TABLES}

Table 1. Participant Demographics and Marathon History..................... 16 


\section{CHAPTER 1: INTRODUCTION}

Monday April 15, 2013 was shaping up to be a marathon Monday just like any of the 116 before it in the city of Boston. Sadly, this particular event turned out to be vastly different than any other Boston Marathon. As the public record indicates, two homemade bombs detonated only 12 seconds apart near the finish line (Seelye, Schmidt \& Rashbaum, 2013). The bombings, which killed three and injured nearly 250 spectators (Seelye et al., 2013), were later determined to be a terror attack. In the days following the bombings, a heightened sense of fear permeated the greater Boston area and the nation. Surveillance footage from a restaurant near the finish line obtained by police showed the Tsarnaev brothers near the finish line. Dzhokhar Tsarnaev was seen putting his backpack on the ground. Ten seconds after the first bomb exploded, he was shown calmly fleeing the scene without his backpack (Seeyle, et al., 2013).

Large-scale sporting events have been the target of terror attacks for decades (Bliss, 2011; Galily, Yarchi, Tamir, \& Samuel-Azran, 2016; Spaaij \& Hamm, 2015; Toohey, Taylor, \& Lee, 2003). Terrorism is defined as "premediated, politically motivated violence perpetrated against noncombatant targets by subnational groups or clandestine agents, usually intended to influence an audience" (United States Department of State, 2004, p. xii). Large-scale sporting events are appealing targets for terror attacks because they attract a large group of people at a single location. Not only are sporting events ideal for harming a crowd of people in a single locale, but such large-scale events draw participants from all over the world, and receive substantial media coverage (Bliss, 2011). The widespread coverage of these events draws media attention from all over the 
world, often exacerbating the widespread fear and panic that accompany terror attacks (Ganor, 2005; Spaaij \& Hamm, 2015).

While it is beyond the scope of this paper to detail every sport-related terrorist attack, athletic events have been the scene of several notable attacks. For example, at the 1972 Olympic Games the Palestinian terrorist organization, Black September, ambushed the Olympic village and killed 11 Israeli athletes (Bliss, 2011; Galily et al., 2016; Toohey, et al., 2003). Since then, there have been a bombing at the 1996 Olympics that killed one and injured 100, a bombing before a Real Madrid versus F.C. Barcelona semifinal championship game in 2002, the first cancellation of the Dakar Car Rally in the event's 30 year history due to threats of a terror attack, a bomb attack at Stockholm's Olympic stadium by a group opposed to Sweden's 2004 Olympic bid, the shooting of a Sri Lankan cricket team's bus in 2008, an attack on the Togo national football team's bus that killed three, a suicide bomb at the start of a Sri Lankan marathon that killed 12 and injured 100, and most recently the Boston Marathon bombings in 2013 (Bliss, 2011; Galily et al., 2016; Spaaij \& Hamm, 2015).

Aside from killing or injuring participants and fans, terror attacks are intended to incite fear and psychological trauma in victims (Bobo, Keller, Greenberg, Alfonzo, Pastor, \& Grieger, 2006; Ganor, 2005). This is because the victims' sense of safety is manipulated by maladaptive fear/trauma schemas (Foa, Huppert, \& Cahill, 2006; Foa \& Kozak, 1986; Ganor, 2005; Halloway \& Fullerton, 1994). As previous sport psychology research has indicated, the Boston Marathon bombings were a traumatic experience for those present at the event (Timm, Kamphoff, Galli, \& Gonzalez, 2017). 
Within mainstream psychology, scholars have theorized that individuals directly exposed to trauma tend to avoid the site or source of trauma (Ehlers \& Clark, 2000; Foa et al., 2006; Foa \& Kozak, 1986). However, based on Emotional Processing Theory, Foa and Kozak (1986) propose that a return to the trauma site via in vivo exposure is beneficial and reduces trauma symptoms (Ehlers \& Clark, 2000; Foa et al., 2006; Foa \& Kozak, 1986). A desire to return to the trauma site is noteworthy because typically those exposed to trauma avoid reminders of the trauma and/or the trauma site itself (Ehlers \& Clark, 2000; Foa et al., 2006; Foa \& Kozak, 1986; Herman, 1998). Avoidance in persons exposed to trauma is due to having developed a fear/trauma schema. A fear/trauma schema is essentially a guide represented in the mind of the person exposed to the trauma and it dictates what his or her actions and behaviors will be when he or she encounters the feared stimulus. In other words, because one has experienced the event and reacted to it before, one already has a blueprint in one's mind for how to react to it again. The individual will continue to react as he or she has in the past unless the mind's blueprint is changed via new, corrective information about the traumatic event (Foa et al., 2006; Foa \& Kozak, 1986).

Traditionally, Emotional Processing Theory has been used with quantitative research methodologies to demonstrate the effectiveness of exposure in reducing negative trauma symptoms in populations with public speaking phobias (Finn, Sawyer, \& Schrodt, 2009), populations with cockroach phobias (Berle, 2007), rape victims (Foa, Molnar, \& Cashman, 1995), and most commonly, populations with PTSD (Ehlers \& Clark, 2000; Foa et al., 2006; Foa \& Kozak, 1986; Murray, Merritt, \& Grey, 2015a, 2015b; Tolin \& 
Foa, 1999; Zalta, Fisher, McLean, Gillihan, Mintz, Yehuda, \& Foa, 2014). The new information gained during exposure ultimately overrides the existing fear schema in one's mind (Foa et al., 2006; Foa \& Kozak, 1986).

While it is known that sport venues and events provide ideal targets for terror attacks (Bliss, 2011; Galily et al., 2016; Ganor, 2005; Spaaij \& Hamm, 2015; Toohey et al., 2003) and terror attacks have been demonstrated as sources of psychological trauma for the persons exposed (Bobo et al., 2006; Ganor, 2005), there is limited scholarly research on the trauma experiences of individuals exposed to terror attacks. Much of the research following past terror attacks and sport has focused on fans' attendance and sense of safety at sporting events, and facilities management strategies (Hall, Marciani, Phillips, \& Cunningham, 2009; Kalist, 2010; Taylor \& Toohey, 2006, 2007; Toohey et al., 2003; Turris, Lund, \& Bowles, 2014).

Following the 2013 Boston Marathon bombings, scholars focused their research on hospital response and preparedness in the greater Boston area (Nadworny, Davis, Miers, Howrigan, Broderick, Boyd, \& Dunster, 2014; Oser, Shah, \& Gitlin, 2015; Tobert, von Keudell, \& Rodriguez, 2015), the mental health needs of the bombings' first responders (Beinecke, 2014), how the media framed the marathon runners following the attack (Oliver, 2014), and runners' coping strategies and resilience in the wake of the bombings (Timm et al., 2017). There is limited scholarly research on Emotional Processing Theory as it relates to the experiences of individuals directly involved in a terror attack while attending or competing in an athletic event. For example, a database search of qualitative 
research related to Emotional Processing Theory resulted in only a limited number of studies, none of which had any connection to the context of sport or sport psychology.

Sport is a domain in which trauma experiences have been explored qualitatively, but at present, athletes' experience of a terror attack has not been adequately studied. For example, Day, Bond, and Smith (2013) examined coaches' experience of vicarious trauma after witnessing one of their athletes endure a serious injury. Similarly, Day and Schubert (2012) studied the experiences of gymnasts who experienced vicarious trauma after seeing a teammate endure a serious injury. Another form of trauma explored qualitatively in the sport psychology literature was the death of a teammate. Kerr's (2007) case study examined an athlete's withdrawal from skydiving after a teammate was killed in a skydiving accident.

Of direct relevance to the present study, Timm and colleagues (2017) examined trauma as it relates to resilience in 2013 Boston Marathoners. Specifically, Timm and colleagues (2017) were interested in runners' resilience following the bombings when framed as an aversive event. While previous Emotional Processing Theory scholars have suggested that avoidance of the trauma site would typically be expected (Ehlers \& Clark, 2000; Foa et al., 2006; Foa \& Kozak, 1986; Herman, 1998), interestingly, 13 of the 16 runners sampled in Timm and colleagues' (2017) study indicated that they planned to rerun the Boston Marathon. This observation is noteworthy because it offers sport psychology scholars the opportunity to study "the perspectives of runners who experienced the 2013 Boston Marathon bombings" (Timm et al., 2013, p. 43) since past research "has not involved the experience of stress or adversity from outside the rules or 
expectations of sport" (Timm et al., 2017, p. 43). Therefore, the purpose of this study was to qualitatively build on Timm et al.'s (2017) work by exploring the meanings athletes ascribed to their experience of re-running the Boston Marathon after being exposed to the 2013 bombings using interpretative phenomenological analysis.

Interpretative phenomenological analysis (IPA) is a methodology best suited for exploring the meaning of runners' return to the Boston Marathon because researchers employing IPA attempt to make sense of the participant making sense of an experience (Pietkiewicz \& Smith, 2014; Smith \& Osborn, 2015). In addition, IPA has been used previously by researchers to explore trauma experiences. For example, IPA has been used to explore the meanings adults with intellectual disabilities ascribed to their trauma experiences (Mitchell, Clegg, \& Fruniss, 2006), the experience of an acquired traumatic brain injury (Howes, Benton, \& Edwards, 2005), the experience of achieving posttraumatic growth following injury in a car accident (Wang, Wang, \& Liu, 2011), and to better understand the experiences of persons bereaved by suicide (Smith, Joseph, \& Nair, 2011). More closely in line with the aims of the present study, Freh and colleagues (Freh, Dallos, \& Chung, 2012) conducted an interpretative phenomenological analysis to explore the experience of surviving a bombing in Iraq. Freh and colleagues (Freh et al., 2012) were concerned with identifying the meaning that survivors ascribed to this unique experience. Similarly, McCormack and McKellar (2015) conducted a longitudinal study that employed interpretative phenomenological analysis with survivors of the 2002 Bali bombings to assess the bombings' impact on survivors' psychological well-being in the years following the attack. 
Sport psychology researchers utilizing interpretative phenomenological analysis have conducted research on, rugby players' experiences of captaincy (Cotterill \& Cheetham, 2017), Olympic swimmers' experiences following adversity (Howells \& Fletcher, 2016), competition's meaning and its impact on collegiate sport experiences of male and female athletes (Warner \& Dixon, 2015), exploring the lived experiences of former National Hockey League athletes with symptoms of multiple concussions (Caron, Bloom, Johnston, \& Sabison, 2013), recreational athletes' rehabilitation adherence experiences (Levy, Polman, Nicholls, \& Merchant, 2009), and the experiences and meanings elite female gymnasts' retirement had on their identity at the conclusion of their careers (Lavallee \& Robinson, 2007; Warriner \& Lavallee, 2008). While these studies employed interpretative phenomenological analysis to understand how athletes made sense of a specific athletic experience, few sport psychology scholars have studied athletes' experiences of a terrorist attack during a competition, and the experience of returning to the same site to compete

In summary, because terror attacks are known trauma sources (Bobo et al., 2006; Galea, Ahern, Resnick, Kilpatrick, Bucuvalas, Gold, \& Vlahov, 2002; Grunfeld, 2006; Silver, Holman, McIntosh, Poulin, \& Gil-Rivas, 2002; Tomb, 1994; Trappler, 2007), major sporting events have been prior targets of successful terror attacks (Bliss, 2011; Galily et al., 2016; Toohey et al., 2003; Spaaij \& Hamm, 2015), and past research in sport "has not involved the experience of stress or adversity from outside the rules or expectations of sport" (Timm et al., 2017, p. 43), 2013 Boston Marathoners provided an 
ideal population to qualitatively study the experience of an in vivo return to the trauma site in sport.

\section{Statement of Purpose}

The purpose of the present study was to explore the meanings athletes ascribed to their experience of re-running the Boston Marathon after being exposed to the 2013 bombings using interpretative phenomenological analysis (IPA).

\section{Definitions}

Emotional processing theory. Asserts that after one experiences or witnesses a traumatic event, one avoids the feared stimulus/cause of the trauma. This kind of coping behavior is due to having developed what is best articulated as a fear/trauma schema. The schema is the representation in the mind of the traumatic event and the associated behavioral and emotional responses to this event or experience. Corrective information from a subsequent exposure to the stimuli overrides the existing fear schema and creates a new, more adaptive schema (Ehlers \& Clark 2000; Foa et al., 2006; Foa \& Kozak, 1986).

In vivo exposure. This is a process by which one obtains new, corrective information to alter one's schema. The individual sees that the new information is incompatible with the existing trauma schema that has guided his or her behavior thus far. The more accurate information replaces the old schema and becomes the new guide for the individual's behavioral responses when he or she has a future encounter with the trauma stimulus (Ehlers \& Clark, 2000; Foa et al., 2006; Foa \& Kozak, 1986). 
Interpretative phenomenological analysis (IPA). Explores how individuals make sense of a specific experience. Researchers using IPA attempt to make sense of the participant making sense of an experience (Pietkiewicz \& Smith, 2014; Smith \& Osborn, 2015).

Terrorism. "Premediated, politically motivated violence perpetrated against noncombatant targets by subnational groups or clandestine agents, usually intended to influence an audience” (United States Department of State, 2004, p. xii).

\section{Limitation}

This study took place four years after the 2013 Boston Marathon bombings. Participants' recall ability may influence the results, because participants could only fully describe their experiences at the time of the present study.

\section{Delimitations}

1. Participants were required to have participated in the 2013 Boston Marathon.

2. Participants were required to have completed a post-2013 Boston Marathon. 


\title{
An Interpretative Phenomenological Analysis of 2013 Boston Marathoners' Experience of Running a Subsequent Boston Marathon
}

\author{
Allison Grace, Ted M. Butryn, Tamar Z. Semerjian, and Cole G. Armstrong \\ San José State University
}

While trauma experiences have been explored in several sport-related research studies, there is a lack of research on athletes' experiences of a terror attack in sport. The present study qualitatively examined the meanings 2013 Boston Marathoners ascribed to their experience of returning to the Boston Marathon to compete. Eight participants took part in semi-structured interviews. Interviews were analyzed via interpretative phenomenological analysis. Eight themes emerged and were organized temporally around pre-2013 Boston Marathon experience, 2013 Boston Marathon experience, and post-2013 Boston Marathon experience. Results suggest participants initially had difficulty processing their experience, but a return resulted in a changed perspective on the sport. Results also suggest returning to the Boston Marathon provided an outlet for some participants to demonstrate their defiance to the attackers, display resilience, and achieve a goal they could not in 2013. Results are interpreted within the context of Foa and Kozak's (1986) Emotional Processing Theory.

Keywords: terrorism, emotional processing theory, trauma, in vivo exposure

April 15, 2013 was a Boston Marathon unlike any of the 116 before it in the city of Boston. Two homemade bombs detonated 12 seconds apart near the finish line. The bombings, later determined to be a terror attack, killed three and injured nearly 250 spectators. Surveillance footage from a restaurant near the finish line obtained by police showed the Tsarnaev brothers near the finish line. Dzhokhar Tsarnaev was seen putting his backpack on the ground. Ten seconds after the first bomb exploded, he was shown calmly fleeing the scene without his backpack (Seelye, Schmidt, \& Rashbuam, 2013).

While it is beyond the capacity of this study to detail every sport-related terror attack, terrorists have targeted large-scale sporting events for decades, most recently the 2013 
Boston Marathon bombings (Bliss, 2011; Galily, Yarchi, Tamir, \& Samuel-Azran, 2016; Toohey, Taylor, \& Lee, 2003).

Terrorism is operationalized as, "premeditated, politically motivated violence perpetrated against noncombatant targets by subnational groups or clandestine agents, usually intended to influence an audience" (United States State Department, 2004, p. xii). In addition to fear, terror attacks are intended to create psychological trauma in victims because victims' sense of safety is manipulated by maladaptive fear/trauma schemas (Bobo, Keller, Greenberg, Alfonzo, Pastor, \& Grieger, 2006; Foa, Huppert, \& Cahill, 2006; Foa \& Kozak, 1986; Ganor, 2005, 2008; Halloway \& Fullerton, 1994). The Boston Marathon bombings were a traumatic experience for those present at the event, and typically individuals directly exposed to trauma tend to avoid the site or source of trauma (Foa et al., 2006; Foa \& Kozak, 1986; Timm, Kamphoff, Galli, \& Gonzalez, 2017). Emotional Processing Theory posits that a return to the trauma site via in vivo exposure is beneficial and reduces trauma symptoms (Ehlers \& Clark, 2000; Foa et al., 2006; Foa \& Kozak, 1986). Avoidance in persons exposed to trauma is due to having developed a fear/trauma schema.

The schema is a guide represented in the mind of the person exposed to the trauma and it dictates what his or her actions and behaviors will be when he or she encounters the feared stimulus. In other words, because one has experienced the event and reacted to it before, one already has a blueprint in one's mind for how one will react to it again. The individual will continue to react as he or she has in the past unless the mind's blueprint is changed (Foa et al., 2006; Foa \& Kozak, 1986). According to Emotional 
Processing Theory, one can learn to engage one's fear/trauma schema and learn that the event or experience is not dangerous. The subsequent exposure to the feared stimuli exposes one to new, corrective information about the traumatic event. The new information ultimately overrides the existing fear schema in one's mind (Foa et al., 2006; Foa \& Kozak, 1986). Emotional Processing Theory has been used by researchers to demonstrate the effectiveness of exposure in reducing negative trauma symptoms in populations with public speaking phobias (Finn, Sawyer, \& Schrodt, 2009), populations with cockroach phobias (Berle, 2007), rape victims (Foa, Molnar, \& Cashman, 1995), and most commonly, populations with PTSD (Foa \& Kozak, 1986; Murray, Merritt, \& Grey, 2015a, 2015b; Tolin \& Foa, 1999; Zalta, Fisher, McLean, Gillihan, Mintz, Yehuda, \& Foa, 2014).

While it is known that sport venues and events provide ideal targets for terror attacks (Bliss, 2011; Galily et al., 2016; Ganor, 2005; Spaaij \& Hamm, 2015; Toohey et al., 2003), a majority of the researchers examining the relationship between sport and terrorism have explored the impact of terrorism on sport fans' sense of safety at sporting events, whether prior attacks influenced fans' decisions to travel to attend sporting events, and facilities management strategies (Taylor \& Toohey, 2006, 2007; Turris, Lund, \& Bowles, 2014). Further, while terror attacks have been demonstrated as sources of psychological trauma for the individuals exposed (Bobo et al., 2006; Ganor, 2005), there is a lack of research on the trauma experiences of persons exposed to terror attacks. A database search of qualitative research related to 
Emotional Processing Theory resulted in only a limited number of studies, none of which had any connection to the context of sport or sport psychology.

After the 2013 Boston Marathon bombings, scholars focused their research on hospital response and preparedness in the greater Boston area (Nadworny, Davis, Miers, Howrigan, Broderick, Boyd, \& Dunster, 2014; Oser, Shah, \& Gitlin, 2015; Tobert, von Keudell, \& Rodriguez, 2015), the mental health needs of the bombings' first responders (Beinecke, 2014), how the media framed the marathon runners following the attack (Oliver, 2014), and runners' coping strategies and resilience in the wake of the bombings (Timm et al., 2017). There is limited scholarly research on Emotional Processing Theory as it relates to the experiences of individuals directly involved in a terror attack while attending or competing in an athletic event.

While not informed by Emotional Processing Theory, Timm and colleagues' (2017) examined trauma as it relates to resilience in 2013 Boston Marathoners. Specifically, Timm et al. (2017) were interested in runners' resilience following the bombings when framed as an aversive event. Interestingly, of direct relevance to the present study, 13 of the 16 runners sampled in Timm and colleagues' (2017) study indicated that they planned to re-run the Boston Marathon. Athletes who have experienced a terror attack directly, and suggested they intended to return to the same site to compete, made them an ideal population to study since scholars who have examined Emotional Processing Theory previously have suggested that avoidance of the trauma site would be expected (Ehlers \& Clark, 2000; Foa et al., 2006; Foa \& Kozak, 1986; Herman, 1998). 
Emotional Processing Theory was used to inform the interview guide for the present study and to interpret "the perspectives of runners who experienced the 2013 Boston Marathon bombings" (p. 43). The aim of the present study was to explore the meanings athletes ascribed to their experience of re-running the Boston Marathon after being exposed to the 2013 bombings using interpretative phenomenological analysis.

Interpretative phenomenological analysis (IPA) is a qualitative methodology best suited for exploring how individuals make sense of a specific experience. Researchers using IPA attempt to make sense of a participant making sense of an experience (Pietkiewicz \& Smith, 2014; Smith \& Osborn, 2015). Additionally, IPA has been used previously to explore trauma experiences (e.g., Howes, Benton, \& Edwards, 2005; Mitchell, Clegg, \& Furniss, 2006; Wang, Wang, \& Liu, 2011), terrorism experiences (e.g. Freh, Dallos, \& Chung, 2012; McCormack \& McKellar, 2015), and trauma experiences in sport (e.g. Caron, Bloom, Johnston, \& Sabiston, 2013; Cotterill \& Cheetham, 2017; Howells \& Fletcher, 2016; Lavallee \& Robinson, 2007; Levy, Polman, Nicholls, \& Merchant, 2009; Warner \& Dixon, 2015; Warriner \& Lavallee, 2008).

In summary, because terror attacks are known trauma sources (Bobo et al., 2006; Galea, Ahern, Resnick, Kilpatrick, Bucuvalas, Gold, \& Vlahov, 2002; Grunfeld, 2006; Silver, Holman, McIntosh, Poulin, \& Gil-Rivas, 2002; Tomb, 1994; Trappler, 2007), major sporting events have been prior targets of successful terror attacks (Bliss, 2011; Galily et al., 2016; Toohey et al., 2003; Spaaij \& Hamm, 2015), and past 
research in sport "has not involved the experience of stress or adversity from outside the rules or expectations of sport" (Timm et al., 2017, p. 43), 2013 Boston Marathoners provided an ideal population to qualitatively study the experience of an in vivo return to the trauma site in sport.

\section{Methods}

This section details the participant selection process and inclusion criteria for the present study, the data collection process, and the data analysis procedures utilized. This section concludes with the criteria used to establish academic rigor, or what Tracy (2010) simply calls quality.

\section{Participants}

The present study included eight participants, which was consistent with previous research utilizing IPA (Freeman, 2016; Freh et al., 2012; Pietkiewicz \& Smith, 2014; Smith \& Osborn, 2015). Participants included three female and five male runners who ranged in age from 29 to 55 years old with a mean age of 36.63 years old.

All participants were required to have participated in the 2013 Boston Marathon and to have completed a post-2013 Boston Marathon. Participants were not required to have actually completed the 2013 Boston Marathon, as the bombings resulted in the cancellation of the remainder of the 2013 Boston Marathon. However, participants who completed the 2013 Boston Marathon prior to the bombs' detonation were not excluded from the study. Participants completed a brief demographic questionnaire. Table 1 includes participant demographic information and information about participants' marathon history. 
Table 1

Participant Demographics and Marathon History

\begin{tabular}{lllll}
\hline Name & Age & Race/Ethnicity & Marathon Total & Boston Marathon Total \\
\hline Andrew & 47 & Caucasian/European-American & 15 & 7 \\
James & 35 & Caucasian/European-American & 9 & 6 \\
Jennifer & 55 & Asian/Asian-American & 25 & 2 \\
Mary & 36 & Caucasian/European-American & 5 & 3 \\
Michael & 29 & Other & 4 & 2 \\
Robert & 31 & Caucasian/European-American & 5 & 2 \\
Sarah & 31 & Caucasian/European-American & 8 & 3 \\
Tom & 29 & Caucasian/European-American & 4 & 3 \\
\hline
\end{tabular}

Participants were recruited via purposeful sampling (Smith \& Osborn, 2015) and snowballing from the researcher's personal contacts, several of whom were in the 2013 race. Purposeful sampling was utilized to find the most appropriate participants capable of providing the most in-depth, rich data (Wilde \& Murray, 2009). For snowballing, potential participants were asked if they knew of any persons (in addition to themselves) who met the inclusion criteria and were interested in participating. In addition, the researcher recruited runners who had run the Boston Marathon in 2013 and a post-2013 Boston Marathon via a brief notice about the study posted on a relevant, popular online running message board. Notices regarding this study were posted on the aforementioned message board seeking volunteers who fit the criteria for inclusion in the study.

\section{Procedure}

Upon receiving Institutional Review Board approval at San José State University and obtaining informed consent from each participant, the researcher conducted semistructured interviews with each participant. Semi-structured interviews were used because this method allowed the researcher's questions to guide the interview process while simultaneously allowing topics identified by the participants to be elaborated upon via probes (Smith \& Osborn, 2015). There is greater flexibility and opportunity to cover 
a broader range of topics with semi-structured interviews (Smith, 2017; Smith \& Osborn, 2015). Interviews were conducted via Skype video conferencing software. Skype was selected because it allowed participants to participate in the interview in a setting of their choice so they would feel comfortable during the interview process (Smith \& Osborn, 2015).

Prior to each interview, the researcher informed participants about the nature of the study. Interviews lasted approximately 30-60 minutes. Each interview was conducted via Skype, audio recorded, and transcribed verbatim by the researcher resulting in 83 total pages of transcribed interview text.

\section{Bracketing Interview}

While bracketing interviews are not always utilized in IPA research, the fact that the researcher was from the Boston area, earned her undergraduate degree in the city of Boston, and was a spectator at several Boston Marathons (including the 2013 Boston Marathon), closely connected her to participants in the present study. As such, it was beneficial for the researcher to take part in a bracketing interview to assist her in acknowledging her implicit biases. The bracketing interview also served to further the present study's academic rigor and refine the interview guide. The bracketing interview was administered by a second researcher with an extensive background in qualitative research generally, and interviewing specifically.

\section{Interview Guide}

Interview questions in the present study were informed by Emotional Processing Theory because it proposes that a return to the trauma site via live (in vivo) exposure is 
beneficial and minimizes trauma symptoms (Ehlers \& Clark, 2000; Foa et al., 2006; Foa \& Kozak, 1986).

The researcher began with an initial question, and later used prompts and probes informed by the interview guide to elicit more detailed information from participants. The researcher first employed more general questions which led to more specific questions, a process Smith and Osborn (2015) label "funneling." The researcher audio recorded each interview after receiving consent from the participants. Participants were assigned pseudonyms, and any personally identifying information was omitted from these records as well.

\section{Data Analysis}

Data analysis followed the procedures for interpretative phenomenological analysis outlined by Smith and Osborn (2015). A single transcript was first read as a whole and subsequently read several more times. In the left-hand margin, the researcher took notes on any interesting content that appeared in the transcripts. This was done for the entire transcript. Next, the researcher identified potential theme titles in the right-hand margin. As Smith and Osborn (2015) note, the potential theme titles were brief and concise in an effort to capture what is essential about the content of the participant's statements. The emergent themes from the right-hand margin of the first transcript were listed in a separate document in the order they appeared. Related themes were grouped into similar, more overarching, superordinate theme categories. Next, the themes and subordinate themes from the first transcript were listed together in a theme table. This analysis process was followed for each of the subsequent interview transcripts and emergent 
theme tables were compared against the theme table from the first transcript's analysis (Smith, 2017; Smith \& Osborn, 2015). Each transcript was analyzed separately because "a distinctive hallmark of IPA is its idiography. IPA is concerned with understanding the case, the experience of each participant, in detail" (Smith, 2017, p. 219). The researcher constructed a final table that consisted of all of the themes from the interview data. Smith and Osborn (2015) note that constructing the final theme table can prove to be difficult because the frequency of the themes is insufficient in warranting their inclusion in the final table. Rather, the ability of the theme to demonstrate the richness of the data in the text is a major consideration for which themes to include in the final theme table.

\section{Academic Rigor}

Academic rigor was established by following Tracy's (2010) criteria for quality as they provide a "common language of qualitative best practices that can be recognized as integral by a variety of audiences" (Tracy, 2010, p. 837). Tracy's (2010) criteria consist of eight components: worthy topic, rich rigor, sincerity, credibility, resonance, significant contribution, ethics, and meaningful coherence.

In addition, a second researcher, not involved in the data collection, functioned as a "critical friend" during the data analysis (Sparkes \& Smith, 2002). The second researcher reviewed the transcripts, provided feedback on themes, and offered alternative data interpretations for reflection upon by the primary researcher (Lundkvist, Gustafsson, Hjälm, \& Hassmén, 2012; Sparkes \& Smith, 2002). 


\section{Results and Discussion}

The purpose of the present study was to explore the meanings that athletes ascribed to their experience of re-running the Boston Marathon after being exposed to the 2013 Boston Marathon bombings. Eight themes emerged from the interview data: running identity; Boston Marathon is a unique race experience; participants' gaining the knowledge there had been an incident at the finish line; how participants made sense of their trauma experience; identification with other terror attacks; safety and security; experiencing the desire to return to the Boston Marathon; and altered worldview. Because participants generally discussed their experiences as a sort of phenomenological journey back to the Boston Marathon, the eight themes were organized temporally around three experiences: pre-2013 Boston Marathon, 2013 Boston Marathon, and post-2013 Boston Marathon. Emergent themes are discussed in the following section along with participant quotations. Participant quotations were selected for inclusion based on their ability to demonstrate the richness of the data and their ability to best characterize the themes (Smith \& Osborn, 2015; Tracy, 2010).

\section{Pre-2013 Boston Marathon}

Running identity. Running identity was related to how participants contextualized their Boston Marathon experience. Participants discussed their experiences from the perspective of the degree to which they self-identified as a "runner" or as a "marathoner." Mary discussed her experience of transitioning from "non-runner" to "runner" leading up to the 2013 Boston Marathon, her very first marathon:

I was like, I'll pick up running, but pretty much just sticking to $5 \mathrm{Ks}$ was the max. And then when I started working...I met a girl who ended up becoming like, my 
really good friend, and she was running the marathon that year and I was like, 'if she can run it, I can run it.' Because she wasn't like, a marathon runner or anything. (Mary)

Other participants self-identified as collegiate runners. For example, Michael recalled:

So at that point, I was only a couple of years done with my collegiate career. I was a little burned out of running, but I still wanted to keep it going. I wasn't one hundred percent burned out that I hated it, but I didn't want to keep running at the same level that I was before...

Michael's collegiate running identity served to distinguish him from others in the running community. Furthermore, his collegiate running identity seemed to motivate him to participate in the Boston Marathon as a means of preserving his running identity. Jennifer contextualized her experience from the perspective of "marathoner:"

I actually had qualified for Boston many times in previous years...running Boston sort of establishes you in a certain category...I guess being a marathoner, and running as many marathons, this was my $26^{\text {th }}$ marathon... And then, so then be able to say, 'I ran Boston too.'

Jennifer's quote established her identity as a marathoner in addition to demonstrating how running the Boston Marathon distinguished her from other marathoners. Specifically, her quote demonstrates how her running identity would transition from "marathoner" to "Boston Marathoner" after the 2013 race. While all of the participants self-identified as "runner" in varying capacities, their having participated specifically in the Boston Marathon was something that distinguished them from others in the running community. In other words, while many individuals in the running community selfidentify as "runners," not all runners can identify as "Boston Marathoner" and as Jennifer noted, not all runners or marathoners are able to say, "I ran Boston too." 


\section{Boston Marathon}

Boston Marathon is a unique race experience. This theme involved participants' experiencing the Boston Marathon as a unique race for two reasons: spectators' energy and enthusiasm and the prestige associated with the event. A majority of the participants experienced the Boston Marathon as unique from other marathons because of the spectators' energy and enthusiasm during the race. For example, one participant explained his experience of spectators' enthusiasm during the race:

The one thing that totally blew my mind... so I ran competitively in high school and college, and as you know, track and field and cross country in college is not the most, you know, spectator sport in the world. Like, basically your parents come and your teammates cheer for you. So, you know, you don't usually have a ton of encouragement. Throughout the whole time, especially when I was absolutely struggling these random people along the course were just so happy. Like, they're just like, 'keep going!' 'you've got this!' like, 'start running again!'... and it was just so encouraging. And even in the moment, I was getting overwhelmed with how cool people really are. And I've never had a feeling like this ever, like at a road race or a cross country meet. It was truly awesome. These random people who have no idea who you are, what your background is, are totally supporting you. (Tom)

About half of the participants acknowledged that spectators' enthusiasm and the prestige associated with the Boston Marathon were factors that made the experience of running their very first Boston Marathon special and had established a race day routine for their subsequent Boston Marathons. The other half of the participants stated that the Boston Marathon is a unique race each year because of the prestige associated with the event. For example, Robert noted that:

It's special...it's my favorite one. The history is a big part of it, the legacy of the event, the history in the city. Really, it's mostly the city and the people in the city and how into the whole thing, the day, and the civic pride... It's on a holiday, Patriot's Day, so the turnout is pretty incredible... 
Robert went on to say, "I definitely recognize the prestige of that particular marathon...but also just maybe even more so because people do know that you have to qualify for it." It could be interpreted that the prestige associated with the Boston Marathon was a factor that participants felt distinguished this marathon from other marathons.

\section{Participants' experiences of gaining the knowledge there had been an incident at}

the finish line. This theme was characterized by shock and confusion. For example, Jennifer recalled being notified of the incident while still on the course:

I think I was anywhere from a mile, to three-quarters of a mile from the finish and I knew because they had the military people with rifles on the course as people were coming towards them with rifles saying, 'turn around'...And we were like, 'what?' you know, the group of, there was a whole big group, it just didn't even make sense. Like, you want us to turn around when we're almost done?

Sarah, who had finished the race, was sitting down a few blocks away from the finish line when she heard the explosion:

I think I heard someone say, like 'oh what was that? It was probably just a cannon for Patriots Day that they shot off,' or fireworks. I thought like worst-case scenario, some scaffolding over the finish line fell or something. The last thing on your mind is that a bomb went off.

Michael also recalled his experience of confusion while gaining the awareness there had been an incident at the finish line:

And then I meet up with my friends. Who look, like, a little confused and I'm just like 'what happened?' And they're like well, no one knows. So, at the time, I thought, like they had tried to do some fireworks, some fireworks accident or something. So, we weren't really sure what went on.

Participants' experiences of shock and confusion are not only consistent with previous research on 2013 Boston Marathoners' experiences of the bombings (e.g. Timm et al., 
2017), but also with research on individuals' experiences following trauma or terrorism (e.g. Bobo et al., 2006; Ehlers \& Clark, 2000; Foa et al., 2006; Foa \& Kozak, 1986;

Ganor, 2005), and terrorism experiences explored via interpretative phenomenological analysis (Freh et al., 2012). These similarities might suggest that the same mechanisms used to emotionally process the experience of a terror attack in other contexts are used to emotionally process the experience of a terror attack in sport (Bobo et al., 2006; Ehlers \& Clark, 2000; Foa et al., 2006; Foa \& Kozak, 1986; Ganor, 2005; Timm et al., 2017). Timm and colleagues identified "surreal race day experience" as a major theme in their research. Surreal race day experience was characterized by confusion and disbelief in Timm and colleagues' (2017) research, which is in line with the present study.

How participants made sense of their trauma experiences. Several of the participants also experienced difficulty while trying to process what they had experienced during the 2013 Boston Marathon. For example, Michael recalled his experience later that evening:

I remember I couldn't sleep that night because at that point they thought that there were other bombs, so I remember thinking, what if some random bomb goes off outside, or near the house? I remember I was pretty anxious that night. It was hard to sleep for me.

Sarah experienced more difficulty attempting to process her emotions:

I guess in shock, you know? Like it doesn't feel real? Like, okay, I should be showing some kind of emotion but I'm not... I should be crying, I should be feeling upset, I should be like, sad but just like, there was no feeling, it was super strange. I started figuring what's happening, but still not processing it, like processing emotions at all. I was just kind of in a state of shock....

Four of the participants experienced shock or disbelief that the attackers would target this specific event and the individuals present for it. One participant experienced anxiety due 
to concern more attacks had been planned in the city of Boston, and that he could be present during a subsequent attack. Three participants experienced a lack of emotion when they attempted to make sense of their bombing experiences. For example, Sarah indicated that she initially had difficulty processing her experience following the 2013 Boston Marathon. This kind of experience is not uncommon following exposure to trauma as Ehlers and Clark assert, "symptoms such as...numbing are common reactions shortly after a traumatic event" (2000, p. 323) and Emotional Processing Theory researchers have suggested there could be a delay in one's emotional processing of trauma following a traumatic experience (Foa et al., 2006).

An alternative explanation for Sarah's delay in her processing could be that she was not sufficiently emotionally engaged with the bombing when it occurred, which led to difficulty processing this experience later on (Foa et al., 2006). Foa and colleagues state, "a delay in peak emotional reaction to a traumatic event may also be seen as initial interference in emotional engagement and thus is expected to hinder emotional processing..." (Foa et al., 2006, p. 12). In other words, because Sarah did not have a strong emotional reaction to the bombings shortly after they occurred, this lack of engagement might have made the experience more difficult to process. Within the context of Emotional Processing Theory, it also offers a possible explanation for why Sarah seemed to process her experience at a later time.

Identification with other terror attacks. This theme was characterized by participants framing their terrorism experience within the broader context of other terror 
attacks, such as the attacks on September $11^{\text {th }}, 2001$. Some participants experienced a

connection to other terror attacks or to the victims of other terror attacks.

This was really devastating, but imagine what $9 / 11$ must have been like? This is just like super small compared to what happened there. And I'm like, God, I wonder how the people in Manhattan, you know downtown Manhattan felt on 9/11 if I'm feeling like this now, it was strange... (Andrew)

Others experienced a sense of "that could have been me," which is not uncommon

following a terror attack (Halloway \& Fullerton, 1994):

Somebody posted a video of the actual finish line and the first bomb went off and that was when I saw the clock and I think the clock read around like 4:09 something, and I actually crossed, when I crossed the finish line...my chip time was 3:59 and the gun time was 4:03. So when I saw that, and realizing how close it was, that was when I just, like, started like, balling... Had I walked any more and gotten there right when it went off, had I hung out by the finish line longer, you know you start thinking, 'what if, what if?' (Sarah)

Tom described his personalization of the attack:

So, my parents and my wife were standing at the spot the first bomb went off the entire day, you know, literally where the first bomb went off, the entire day... and they left that spot about twenty minutes before it happened to meet me...I just remember being so distraught about that. Like, what if I didn't run as much that last mile, or two miles? I just remember being so upset about it because running for me has been such a huge part of my life. And I thought about what it would mean to me if I actually had, you know, for lack of a better word, skin in the game, in this one...someone that I know and love got hurt or killed by it, like what would that do to me?

Interestingly, two of the participants felt they had experienced the bombing in a similar way to persons not present for the attack, and while having participated in the race that day, they experienced detachment from the events of April 15, 2013. For example, one participant compared his experience of the 2013 Boston Marathon bombings to that of a spectator: 
Yeah, I mean, in many ways I felt like a spectator. Because the whole way, because, I had left the course at the time that it happened...But yeah, it was kind of... surreal, because I had just been there. I felt really distant from it and like I was seeing it the same way everyone else was...I guess it felt like I was more observing it than I had actually been there. (Robert)

Seeking connection to other terror attacks in the wake of a recent terror attack has been observed in past research (e.g. Ganor, 2005). However, some participants in the present study experienced the bombings in a similar way to individuals not present at the event. In other words, while having participated in the race that day, some participants, like Robert, experienced a sense of distance from the events of April 15, 2013. Experiencing a terror attack this way is unusual and contrary to what would be anticipated from an individual exposed to a terror attack (Ganor, 2005; Halloway \& Fullerton, 1994).

\section{Post-2013 Boston Marathon}

Experiencing the desire to return to the Boston Marathon. This theme emerged from participants experiencing the desire to return to run a post-2013 Boston Marathon. Three participants experienced collective motivations to return, while two specified more individualized motivations, the remainder stated they intended to return because it was an event they had participated in each year and would continue to participate in. For example, one participant recalled not being able to achieve a personal goal:

It was kind of, obviously, very upsetting and sad what happened, but I was also personally upset because I had set this goal for myself and I had it taken away from me. And if I had failed because of me, then that's one thing, but knowing that I was going to do it and had that taken away from me... I'm somewhat stubborn, and it's like that's not right... I don't know when it actually clicked, but I just knew that I had to do whatever I could possibly do to come back the next year and show that one, I could do it and, two, that I'm not afraid. (Mary)

Tom discussed his experience of wanting to return for collective reasons: 
We're going to be there because, you know, I want to be there. It's going to be healing for me. It's going to be all the emotions and I knew I had to do it. I knew for my own sanity that I had to do it. Because, you know, I just don't believe in living this life of 'well something may happen to me today'... But you know coming back here, and standing right in the spot of one of those bombs and being like, 'you're not going to dictate my life, you're not going to ruin this event for any of us' 'you didn't win, you didn't accomplish what you wanted to accomplish.'

Jennifer had a similar experience:

I think I felt like I wanted to do more at the time...I didn't know what to do and this was the only way I knew that I could come back and be part of this resilient, worldwide surge of, you know, 'you can't mess with us,' and do it in a way that was peaceful, and an experience with other people... not finishing the marathon is one thing, but supporting all these people, people who died, people who were maimed, people just in spirit in general, that was unfinished for me.

These findings echoed the reasons that participants in Timm and colleagues' research cited for why they intended to return to complete a post-2013 Boston Marathon (Timm et al., 2017). Contrary to what would be expected following trauma per Emotional Processing Theory, participants in the present study self-initiated a return to the trauma site (Ehlers \& Clark, 2000; Foa et al., 2006; Foa \& Kozak, 1986). Participants experienced not only the desire to return to the trauma site by running a subsequent Boston Marathon, some participants, like Tom and Jennifer, seemed to experience an obligation to return to this site. The obligation to return seemed rooted in what could be best articulated as a "peaceful defiance." While some of the participants experienced anger towards the terrorists and were deprived of a personal goal, others experienced their return to the Boston Marathon as an expression of defiance towards the attackers and experienced re-running as a way to express their support for one another and the victims through sport. 
Safety and security. Two participants experienced concern for their safety, while four participants experienced little or no concern for their safety during their post-2013 Boston Marathon. The remaining participants did not allude to any concerns or lack thereof. Mary experienced some concern and stated, "There was some concern that like, okay, well this happened last year, is it going to happen again this year, or is it going to happen somewhere else on the course?" Mary's concern that the trauma site could still be linked to future danger upon her return would be expected based on Emotional Processing Theory (Foa et al., 2006; Foa \& Kozak, 1986). James alluded to similar safety concerns:

I think just the finish line area, you know, I think it was a just a little nerve wracking to go in there which is interesting because I basically travelled that road every day to get to work. So, it's not like I hadn't been back to the area since the bombs went off.

James' experience is particularly noteworthy because although he returned to the area several times since the bombings, his experience suggests that the context in which he returned might have moderated the emotional impact of his experience. In other words, being near the bombing site on the way to work affected him differently than being near the bombing site during the Boston Marathon, the context in which the initial trauma occurred. In contrast, another participant did not experience safety concerns during her return:

I never thought something was going to happen at the finish this time. I knew I felt safe because there were so many more police and firefighters, and all of the service people who are there to protect it...I felt very protected and safe. I did hear some other people saying they weren't sure, you know whatever, but that never crossed my mind. I felt fully safe... (Jennifer)

Tom also experienced safety during his return: 
The Boston Police and the Mass. State Police, and you know, everyone involved, they do a fantastic job of making you feel safe so we don't have to worry about these things. And, actually making it safe, not just feel safe.

While a terror attack would be expected to diminish one's sense of safety (Ganor, 2005; Halloway \& Fullerton, 1994), the majority of the participants sampled in the present study experienced safety and security during their return to the Boston Marathon. These findings are in line with previous research on facilities management strategies, in which researchers determined that increased security measures due to terrorism concerns did not dissuade fans from attending sporting events (Hall et al., 2009; Taylor \& Toohey, 2006, 2007). Participants' experiences in the present study are noteworthy because experiencing safety and security is contrary to what would be expected after experiencing a terror attack. This is because a goal of terrorism is to instill in individuals the "uncertainty, fear, and ongoing anxiety that it [an attack] will happen again" (Shaw, 2013, p. 241). Yet, this did not seem to be on participants' minds during their post-2013 Boston Marathon. One potential explanation for why participants experienced a sense of safety and security during their post-2013 Boston Marathon is because within the context of Emotional Processing Theory, exposure is aimed at:

Helping people to repeatedly confront safe but feared thoughts, sensations, situations, and activities to promote emotional processing. Thus, exposure therapy exercises are explicitly designed to activate the fear structure and at the same time provide corrective information about the nonthreat value of the stimuli. (Foa et al., 2006, p.8)

Because participants were not afraid to return to the Boston Marathon, it could be inferred that participants' 2013 experience did not result in the development of a fear/trauma schema. Emotional Processing Theory researchers propose that avoidance of a trauma is because one perceives this experience or site as dangerous, but if he or she 
never perceived the bombings as dangerous in the first place, one might suspect there is no reason to avoid this site or stimulus, since Foa and Kozak propose, "activating fear may depend on how well it can depict elements of the fear structure" (1986, p. 25). In other words, perhaps the 2013 Boston Marathon bombings did not result in participants feeling they were personally in danger, and therefore they never developed a fear/trauma schema following the bombings. The fact that participants experienced shock and confusion, but not fear, would lend further support to this interpretation.

Timm and colleagues' participants indicated they had coped with the 2013 Boston Marathon bombings by using coping strategies they had used during prior trauma experiences. Timm and colleagues noted, "several participants mentioned acquiring the coping abilities they used to process their experience at the Boston Marathon during previous traumatic experiences..." (2017, p. 47). One participant in the present study alluded to employing a similar strategy:

I guess I've had other experiences in my life, what you might call posttraumatic stress, where you're afraid of, you know, seeing the same things trigger those same emotions. But I guess, at least in the case of Boston, I didn't experience that so much. (Robert)

Likewise, Ehlers and Clark's (2000) research on trauma supports this interpretation as they propose how previous trauma is processed may influence how subsequent trauma is processed. A possible explanation for Robert's experience could be that perhaps he did not develop a fear/trauma schema as a result of his prior trauma experience, but rather Robert's prior trauma experience resulted in his having developed a coping schema. As such, it could be likely that a subsequent traumatic experience, like the Boston Marathon 
bombings, re-activated Robert's coping schema instead of re-activating a fear/trauma schema.

Altered worldview. This theme was characterized by the meaning that participants ascribed to their return to the 2013 Boston Marathon bombings to complete a subsequent Boston Marathon.

It was a little emotional. Like, I felt great passing the street that I had stopped on. And I'm like, 'okay, well I've made it two steps further than I did last year.' But it wasn't until I got to B.C., like a mile later, that I'm like starting the decline and my breath kind of got taken away because it's like you know this is happening, and like, it's going to be okay. (Mary)

Similarly, Jennifer also recalled her experience of being in the same location she had been told to stop during the 2013 race:

I just got down on my hands and knees and I kissed the ground. And, a couple of other people stopped and did the same thing... And then we picked each other up, and then we started jogging together. And I think I was probably crying the whole time after that. I was just crying and thankful for every step.

The majority of the participants experienced an increased emphasis on participating in running for enjoyment versus performance, as well as an increased appreciation for their ability to run at all. For example, Robert said:

I recognize I was very lucky and fortunate...that any day I can run safely and be healthy and be able to, you know, finish a marathon, or run at all...The irony and the sadness wasn't lost on me. You know, people that lived in the attack, many of them had lost legs, you know, and they weren't able to, to run anymore... I think the most, that, I took away from it personally was, you know, that it changed my perspective on the importance of running and that, you know, because of how my attitude shifted in 2013, going from being disappointed about a time or performance, to immediately just being grateful and appreciative that I could run and realizing that, you know, each day that I can do that is a gift and that's not to be taken for granted. 
Scholars suggest that negative outcomes would be expected after one has a traumatic experience. For example, negative worldview has been commonly observed in persons exposed to trauma because of "common post-trauma associations within the fear structure, such that the world in general or specific trauma reminders are dangerous..." (Foa et al., 2006, p. 13; Ehlers \& Clark, 2000; Foa \& Kozak, 1986). The negative associations are from the individual's inability "to see the trauma as a time-limited event that does not have global negative implications for their future" (Ehlers \& Clark, 2000, p. 320). However, contrary to this expectancy, the majority of the participants in the present study experienced positive changes in perspective or worldview following their return. Participants in Timm and colleagues' (2017) research also acknowledged similar positive changes after their 2013 Boston Marathon experience. However, the present study extends Timm and colleagues' (2017) research because, Timm et al.'s (2017) participants indicated they were unsure of how they would react during a subsequent Boston Marathon.

In the present study, the researcher clarifies some of the uncertainty surrounding what a return would be like, or accomplish for runners. Participants in the present study experienced increased sense of appreciation for being able to run at all. Others noted that their experience of the 2013 Boston Marathon bombings and a subsequent Boston Marathon contributed to a change in focus or perspective on running. Instead, their experience allowed them to gain a greater appreciation for the enjoyment of running. Likewise, participants in Timm and colleagues' (2017) study also indicated they no longer took the sport for granted after the 2013 Boston Marathon bombings. One might 
interpret that participants' experiences of the 2013 and post-2013 Boston Marathon initiated a reflection upon their running identity. More specifically, participants' 2013 and post-2013 Boston Marathon experiences may have led participants to consider how a transition from able-bodied to disable-bodied athlete would have impacted their running identity. Essentially, a reflection from this perspective ultimately renewed their relationship with, or outlook on running.

\section{Conclusion and Directions for Future Research}

The purpose of this study was to explore the meanings that 2013 Boston Marathoners ascribed to their experience of returning to the Boston Marathon to compete following the 2013 Boston Marathon bombings. As with prior sporting events targeted in terror attacks, the Boston Marathon provided the attackers with a dense gathering of athletes and spectators, which made it an ideal target for a terror attack (Bliss, 2011; Bobo et al., 2006; Galily et al., 2016; Ganor, 2005; Spaaij \& Hamm, 2015; Toohey et al., 2003). Some of the participants in the present study had experiences often observed following a terror attack such as the anxiety of another impending attack, and personalization of the attack via thoughts of "that could have been me" (Bobo et al., 2006; Galea et al., 2002; Ganor, 2005; Grunfeld, 2006; Silver et al., 2002; Tomb, 1994; Trappler, 2007). Some participants in the present study alluded to still perceiving the finish line as a potential danger site upon their return because of their prior experiences at this location. Perceiving a site of past trauma as dangerous during a subsequent encounter would be anticipated based on Emotional Processing Theory (Ehlers \& Clark; Foa et al., 2006; Foa \& Kozak, 1986). Additionally, some participants also contextualized their experiences 
within the broader context of prior terror attacks like the attacks on September $11^{\text {th }}, 2001$. Identification with prior terror attacks in this way is not uncommon and has been observed in previous research (e.g. Ganor, 2005).

This study was the first in the sport psychology literature in which a researcher qualitatively explored athletes' experience of returning to a location where they experienced a terror attack to compete. Because the present study's aim was to determine how athletes made sense of their experience of a terror attack in sport, interpretative phenomenological analysis was determined to be the methodology best suited for exploring the meaning 2013 Boston Marathoners' ascribed to their return to this site (Freh et al., 2012; Howes et al., 2005; Pietkiewicz \& Smith, 2014; Smith et al., 2011; Smith \& Osborn, 2015; Wang et al., 2011).

This study was also the first in the sport psychology literature in which a researcher used Foa and Kozak's (1986) Emotional Processing Theory as a theoretical framework to interpret the results and to inform an interview guide. While the results of the present study were not fully consistent with Foa and Kozak's (1986) Emotional Processing Theory, the theory provided a unique framework within which to contextualize the emergent themes from the present analysis.

Results of the present study have implications for sport psychology professionals. Specifically, the present study has demonstrated that after experiencing a traumatic event in sport, athletes' experiences were idiosyncratic, which suggests that there is no "one size fits all" approach to working with athletes who have experienced trauma incurred via sport. Results of the present study suggest that while one athlete may develop a 
fear/trauma schema after what many would consider a "normal" traumatic experience, others may not. Research is warranted to gain understanding as to why such varied responses emerge in those who have experienced traumatic events in sport.

\section{Limitations}

Despite the researcher's efforts to gain a more nuanced understanding of athletes' experiences of returning to the site where they experienced a terror attack to compete, this study did have limitations. The first limitation of the present study was when it took place. The Boston Marathon bombings occurred on April 15, 2013. This study was conducted in 2017. Because of this gap in time, recall bias might have influenced participants' responses and ultimately the results. Another limitation of the present study is that while purposeful sampling (Smith \& Osborn, 2015; Wilde \& Murray, 2009) was employed to obtain a sample of participants who participated in the 2013 Boston Marathon and a post-2013 Boston Marathon, none of the participants finished the 2013 race as the bombs exploded.

\section{Directions for Future Research}

The results of this study point to several areas for future research. One area for future research stems from Robert's experience of feeling distant, or removed from an event he had been present for. Essentially, he recalled that he had experienced the Boston Marathon bombings in a similar way as "everyone else," or individuals who had not been present for the event. As the researcher in the present study concluded, trauma experiences are idiosyncratic and there is no one "best practice" solution when working with athletes who have experienced trauma in sport. Therefore, future research is 
encouraged to explore athletes' lack of development of a fear/trauma schema following a traumatic event in sport and the meaning behind the schemas athletes do ultimately develop following a traumatic experience.

It seemed as if athletes' perceived sense of safety influenced, or perhaps moderated, their perception of the likelihood of another attack during their return, and not the development of a fear/trauma schema as would be expected based on Emotional Processing Theory (Foa et al., 2006; Foa \& Kozak, 1986). Further research is warranted to determine the effect of perceived sense of safety on athletes' behaviors when competing at sites of prior terror attacks, as scholars have suggested that terrorism is intended to compromise one's sense of safety or security (Ganor, 2005). There have been similar lines of research in which scholars have explored fans' perceived sense of safety in the wake of attacks, but not athletes' perceived sense of safety when returning to compete at the exact location of an attack (Taylor \& Toohey, 2006, 2007; Taylor, et al., 2003).

Lastly, because athletes' experience of a return and being able to complete a post2013 Boston Marathon may have potentially led them reflect on their running identity from the perspective of transitioning from able-bodied to disable-bodied athlete, further research is warranted to explore the meaning of this actual or hypothetical transition's impact on these athletes' experiences within their sport. Research in this area would be beneficial as there still exists a lack of research exploring sport-related trauma incurred outside of what is anticipated by nature of participation in sport (Timm et al., 2017). 


\section{References:}

Beinecke, R.H. (2014). Assessing the mental health needs of victims and responders to the Boston Marathon bombing. International Journal of Mental Health, 43(2), 17-34.

Berle, D. (2007). Graded exposure therapy for long-standing disgust-related cockroach avoidance in an older male. Clinical Case Studies, 6(4), 339-347. doi: $10.1077 / 1534650106288965$

Bliss, S. (2011). Sport terrorism: A deadly game. Geodate, 24(1), 9-14.

Bobo, W.V., Keller, R.T., Greenberg, N., Alfonzo, C.A., Pastor, L.H., \& Grieger, T.A. (2006). Psychological responses to terrorism. In T.W. Britt, C.A. \& Adler A.B. (Eds.) Military life: The psychology of serving in peace and combat: Vol. 1 (pp. 31-61) Westport, CT: Prager Security International.

Caron, J.G., Bloom, G.A., Johnston, K.A., Sabiston, \& C.M. (2013). Effects of multiple concussions on retired National Hockey League players. Journal of Sport \& Exercise Psychology, 35(2), 168-179.

Cotterill, S.T. \& Cheetham, R. (2017). The experience of captaincy in professional sport: The case of elite professional rugby. European Journal of Sport Science, 17(2), 215-222. doi: 10.1123/jsep.2015-0159

Day, M.C., Bond, K., \& Smith, B. (2013). Holding it together: Coping with vicarious trauma in sport. Psychology of Sport, 14, 1-11. doi:10.1016/j.psychsport.2012.06.001

Day, M.C. \& Schubert, N. (2012). The impact of witnessing athletic injury: A qualitative examination of vicarious trauma in artistic gymnastics. Journal of Sports Sciences, 30(8), 743-753. doi: 10.080/02640414.2012.671530

Ehlers, A., \& Clark, D. M. (2000). A cognitive model of posttraumatic stress disorder. Behaviour Research and Therapy, 38(4), 319-345.

Finn, A.N., Sawyer, C.R., \& Schrodt, P. (2009). Examining the effect of exposure therapy on public speaking state anxiety. Communication Education, 58(1), 92-109. doi: 10.1080/03634520802450549

Foa, E.B., Huppert, J.D., \& Cahill, S.P. (2006). Emotional processing theory: An update. In B.O. Rothbaum (Ed.), Pathological anxiety: Emotional processing in etiology and treatment (3-24). New York, NY: Guilford Press. 
Foa, E.B. \& Kozak, M.J. (1986). Emotional processing of fear: Exposure to corrective information. Psychological Bulletin, 99(1), 20-35. doi: 10.1037/0033-2909.99.1.20

Foa, E.B., Molnar, C., \& Cashman, L. (1995). Change in rape narratives during exposure therapy for posttraumatic stress disorder. Journal of Traumatic Stress, 8(4), 675-690. doi: 10.1002/jts.2490080409

Freeman, K.R. (2016). Exploring the lived experiences of supervising child protection social workers (Doctoral dissertation). Retrieved from http://scholarworks.waldenu.edu/cgi/viewcontent.cgi?article=3755\&context=d issertations

Freh, F. M., Dallos, R., \& Chung, M. C. (2013). An exploration of PTSD and coping strategies: response to the experience of being in a bomb attack in Iraq. Traumatology, 19(2), 87-94.

Galea, S., Ahern, J., Resnick, H., Kilpatrick, D. Bucuvalas, M., Gold, J., \& Vlahov, D. (2002). Psychological sequelae of the September 11 terrorist attacks in New York City. The New England Journal of Medicine, 346, 982-984. doi: 10.1056/NEJMsa013404

Galily, Y., Yarchi, M., Tamir, I., \& Samuel-Azran, T. (2016). Terrorism and sport: A global perspective. American Behavioral Scientist, 60(9), 1039-1042. doi: $10.1177 / 0002764216632839$

Ganor, B. (2005). Terrorism as a strategy of psychological warfare. Journal of Aggression, Maltreatment \& Trauma, 9(1-2), 33-43. doi: 10.1300/J146v901_03

Grunfeld, A. (2006). Post-traumatic stress disorder in the context of terrorism: Key highlights from the recent literature. International Journal of Mental Health and Addiction, 4, 285-287. doi: 10.1007/s11469-006-9042-8

Hall, S., Marciani, L., Phillips, D., \& Cunningham., T. (2009). Spectator perceptions of security management at a NASCAR (National Association for Stock Car Auto Racing) event. The Sport Journal, 12(1).

Halloway, H.C. \& Fullerton, C.S. (1994). The psychology of terror and its aftermath. In R.J. Ursano, B.G. McCaughey, \& C.S. Fullerton (Eds). Individual and community responses to trauma and disaster: The structure of human chaos (31-45). Cambridge, U.K.: Cambridge University Press. 
Herman, J.L. (1998). Recovery from psychological trauma. Psychiatry and Clinical Neurosciences, 52, 145-150.

Howes, H., Benton, D. \& Edwards, S. (2005). Women's experience of brain injury: An interpretative phenomenological analysis. Psychology \& Health, 20(1), 129-142. doi: 10.1080/0887044042000272903

Howells, K. \& Fletcher, D. (2016). Adversarial growth in Olympic swimmers: Constructive reality or illusory self-deceit? Journal of Sport \& Exercise Psychology, 38, 173-186.

Kalist, D.E. (2010). Terror alert levels and Major League Baseball attendance levels. International Journal of Sport Finance, 5, 181-192.

Kerr, J.H. (2007). Sudden withdrawal from skydiving: A case study informed by reversal theory's concept of protective factors. Journal of Applied Sport Psychology, 19, 337-351. doi: 10.1080/10413200701342699

Lavallee, D. \& Robinson, H.K. (2007). In pursuit of an identity: A qualitative exploration of retirement from women's artistic gymnastics. Psychology of Sport \& Exercise, 8(1), 119- 141.

Levy, A.R., Polman, R.C.J., Nicholls, A.R., \& Merchant, D.C. (2009). Sport injury rehabilitation adherence: Perspectives of recreational athletes. International Journal of Sport \& Exercise Psychology, 7(2), 212-230.

Lundkvist, E., Gustafsson, H., Hjälm, S., \& Hassmén, P. (2012). An interpretative phenomenological analysis of burnout and recovery in elite soccer coaches. Qualitative Research in Sport, Exercise and Health, 4(3), 400-419. doi: 10.1080/2159676X.2012.693526

McCormack, L. \& McKellar, L. (2015). Adaptive growth following terrorism: Vigilance and anger as facilitators of post traumatic growth in the aftermath of the Bali bombings. Traumatology, 21(2), 71-81. doi: 10.1037/trm0000025

Mitchell, A., Clegg, J. \& Furniss, F. (2006). Exploring the meaning of trauma with adults with intellectual disabilities. Journal of Applied Research in Intellectual Disabilities, 19(2), 131-142. doi: 10.1111/j.1468-3148.2005.00235.x

Murray, H., Merritt, C., \& Grey, N. (2015). Clients' experiences of returning to the trauma site during PTSD treatment: An exploratory study. Behaviorual and Cognitive Psychotherapy, 43, 1-11. doi: 10.1017/51352465815000338 
Murray, H., Merritt, C., \& Grey, N. (2015). Returning to the scene of the trauma in P TSD treatment - why, how and when? The Cognitive Behavioral Therapist, 8(28), 1-12. doi: 10.1017/S1754470X15000677

Nadworny, D., Davis, K., Miers, C., Howrigan, T., Broderick, E., Boyd, K., \& Dunster, G. (2014). Boston strong - one hospital's response to the 2013 Boston Marathon bombings. Journal of Emergency Nursing, 40(5), 418-427. doi: 10.1016/j.jen.2014.06.007

Oliver, H.L. (2014). Boston strong: A qualitative content analysis of runner portrayal in U.S. newspaper coverage of the Boston Marathon bombings (Master's thesis). Retrieved from http://jhir.library.jhu.edu/

Oser, M., Shah, S.B., \& Gitlin, D. (2015). Psychiatry department response to the Boston Marathon bombings within a level-1 trauma center. Harvard Review of Psychiatry, 23(3), 195-200. doi: 10.1097/HRP.0000000000000049

Pietkiewicz, I., \& Smith, J. A. (2014). A practical guide to using interpretative phenomenological analysis in qualitative research psychology. Psychological Journal, 20(1), 7-14.

Seelye, K.Q., Schmidt, M.S., \& Rashbaum, W.K. (2013, April 23). Surviving suspect is charged by U.S. in Boston attack. The New York Times. Retrieved from http://www.si.com

Shaw, J.A. (2003). Children exposed to war/terrorism. Clinical Child and Family Psychology Review, 6(4), 237-246.

Silver, R.C., Holman, E.A., McIntosh, D.N., Poulin, M., \& Gil-Rivas, V . (2002). Nationwide longitudinal study of psychological responses to September 11. Journal of the American Medical Association, 288(10), 1235-1244.

Smith, A., Joseph, S., \& Nair, R.D. (2011). An interpretative phenomenological analysis of posttraumatic growth in adults bereaved by suicide. Journal of Loss and Trauma, 16(5), 413-430. doi: 10.1080/15325042.2011.572047

Smith, J.A. \& Osborn, M. (2015). Interpretative phenomenological analysis. In J.A. Smith (Ed.), Qualitative Psychology a practical guide to methods (3rd ed., pp. 25-52). London: Sage.

Smith, J.A. (2017). Interpretative phenomenological analysis in sport and exercise. In B. Smith and A.C. Sparks (Eds.), Routledge Handbook of Qualitative Research in Sport and Exercise (pp. 219-229). New York: Routledge. 
Spaaij, R. \& Hamm, M.S. (2015). Endgame? Sports events as symbolic targets in lone wolf terrorism. Studies in Conflict and Terrorism, 38, 1022-1037. doi: 10.1080/1057610X.2015.1076696

Sparkes, A.C. \& Smith, B. (2002). Sport, spinal cord injury, embodied masculinities, and the dilemmas of narrative identity. Men and Masculinities, 4, 258-285. doi: 10.1177/1097184X02004003003

Taylor, T. \& Toohey, K. (2006). Impacts of terrorism-related safety and security measures at a major sport event. Event Management, 9, 199-209.

Taylor, T. \& Toohey, K. (2007). Perceptions of terrorism threats at the 2004 Olympic Games: Implications for sport events. Journal of Sport \& Tourism, 12(2), 99-114. doi: 10.1080/14775080701654754

Timm, K., Kamphoff, C., Galli, N. \& Gonzalez, S.P. (2017). Resilience and growth in marathon runners in the aftermath of the 2013 Boston Marathon Bombings. The Sport Psychologist, 31(1), 42-55. doi: 10.1123/tsp.2015-0053

Tobert, D., von Keudell, A., \& Rodriguez, E.K. (2015). Lessons from the Boston Marathon bombing: An orthapaedic perspective on preparing for high-volume trauma in an urban academic center. Journal of Orthopaedic Trauma, 29(10), 7-10. doi: 10.1097/BOT.0000000000000413

Tolin, D.F. \& Foa, E.B. (1999). Treatment of a police officer with PTSD using prolonged exposure. Behavior Therapy, 30(3), 527-538. doi: 10.1016/S00057894(99)80023-9

Tomb, A. (1994). The phenomenology of post-traumatic stress disorder. Psychiatric Clinics of North America, 17(2), 237-250.

Toohey, K., Taylor, T., \& Lee, C. (2003). The FIFA World Cup 2002: The effects of terrorism on sport tourists. Journal of Sport Tourism, 8(3), 167-185. doi:10.1080/14775080310001690495

Tracy, S.J. (2010). Qualitative quality: Eight "Big Tent" criteria for excellent qualitative research. Qualitative Inquiry, 16(10), 837-851. doi: $10.1177 / 1077800410383121$

Trappler, B. (Ed.) (2007). Modern Terrorism and psychological trauma. New York, NY: Gordian Knot Books. 
Turris, S.A., Lund, A., \& Bowles, R.R. (2014). An analysis of mass casualty incidents in the setting of mass gatherings and special events. Disaster Medicine and Public Healthy Preparedness, 8(2), 143-149. doi: 10.1017/dmp.2014.24

United States Department of State (2004). Patterns of global terrorism. Retrieved from United States Department of State website: https://www.state.gov/documents/organization/31912.pdf

Wang, Y., Wang, J., \& Liu, X. (2011). Posttraumatic growth of injured patients after motor vehicle accidents: An interpretative phenomenological analysis. Journal of Health Psychology, 17(2), 297-208. doi: 10.1177/1359105311410511

Warner, S. \& Dixon, M.A. (2015). Competition, gender and the sport experience: An exploration among college athletes. Sport, Education and Society, 20(4), 527545.

Warriner, K. \& Lavallee, D. (2008). The retirement experiences of elite female gymnasts: Self identity and the physical self. Journal of Applied Sport Psychology, 20(3), 301-318.

Wilde, D. J., \& Murray, C. D. (2009). The evolving self: Finding meaning in neardeath experiences using interpretative phenomenological analysis. Mental Health, Religion and Culture, 12(3), 223-239.

Zalta, A.K., Gillihan, S.J., Fisher, A.J., Mintz, J., McLean, C.P., Yehuda, R., \& Foa, E.B. (2014). Change in negative cognitions associated with PTSD predicts symptom reduction in prolonged exposure. Journal of Consulting and Counseling Psychology, 82(1), 171-175. doi: 10.1037/a003473 


\section{APPENDIX A}

\section{Demographic Information Questionnaire}

Please answer the following items to the best of your ability. If there is an item you would prefer not to answer, please select "prefer not to say". Your responses will be kept confidential and will be used only for the purpose of gathering demographic information. Thank you for your participation!

1. Which gender do you identify as?
Female
Male
Other
Prefer not to say

2. Please specify your age in years:

3. What is your racial/ethnic background?

$\square$ Hispanic/Latino

African/African-American

Caucasian/European-American

Asian/Asian-American

Middle-Eastern

Other (Please specify):

Prefer not to say

4. In what U.S. state or country do you currently reside? (Please specify):

5. Please specify the date of your initial post-2013 Boston Marathon (MM/DD/YYYY)

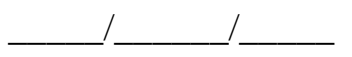

6. How many marathons (total) have you completed? (Please specify a number):

7. How many Boston Marathons have you completed? (Please specify number): 
APPENDIX B

RECRUITMENT NOTICE

INVITATION TO PARTICIPATE IN RESEARCH STUDY ABOUT BOSTON

MARATHONERS!

1. Did you participate in the 2013 Boston Marathon?

2. Have you completed a Boston Marathon since the 2013 Boston Marathon?

3. Are you over the age of 18 ?

If you answered "YES" to the questions above, you may be eligible to participate in the following research study.

The present research study will explore the meanings 2013 Boston Marathoners ascribe to their experience of returning to run a subsequent Boston Marathon in the wake of the 2013 bombings.

Adults (age 18+) who have participated in the 2013 Boston Marathon AND who ran a subsequent (post-2013) Boston Marathon are eligible to participate in the present study.

The study will include a brief questionnaire and a longer, more in-depth Skype interview that can be done at the time and location of your choice.

No compensation is provided for participation.

If you, or someone you know would be interested in participating in this study, or for more information, please contact: bostonmarathonstudy@gmail.com Thank you for your interest!

Allison Grace

Graduate Student Researcher

San José State University

Theodore M. Butryn, Ph.D.

Faculty Advisor

San José State University 


\section{APPENDIX C}

\section{INSTITUTIONAL REVIEW BOARD APPROVAL}
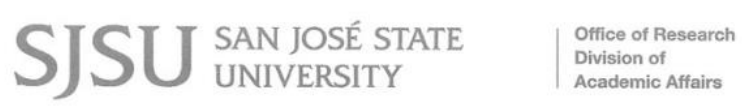

Academic Affairs

To: $\quad$ Allison Grace

From: Pamela C. Stacks, Ph.D. Associate Vice President Office of Research

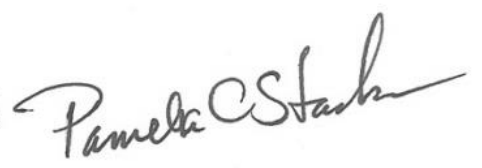

Date: July 13, 2017

The Human Subjects-Institutional Review Board has approved your request to use human subjects in the study entitled:

"An Interpretative Phenomenological Analysis of 2013 Boston Marathoners and Their Experience of Running a Subsequent Boston Marathon"

This approval is contingent upon the subjects participating in your research project being appropriately protected from risk. The approval includes continued monitoring of your research by the Board to assure that the subjects are being adequately and properly protected from such risks. If at any time a subject becomes injured or complains of injury, you must notify Dr. Pamela Stacks immediately. Injury includes but is not limited to bodily harm, psychological trauma, and release of potentially damaging personal information. This approval for the human subject's portion of your project is in effect for one year, and data collection beyond July 13, 2018 requires an extension request.

Please also be advised that all subjects need to be fully informed and aware that their participation in your research project is voluntary, and that he or she may withdraw from the project at any time. Further, a subject's participation, refusal to participate, or withdrawal will not affect any services that the subject is receiving or will receive at the institution in which the research is being conducted. If you have any questions, please contact me at (408) 924-2479.

Protocol \# S17107

cc. Ted Butryn 0054 


\section{APPENDIX D}

\section{INFORMED CONSENT FORM}

\section{REQUEST FOR YOUR PARTICIPATION IN RESEARCH AN INTERPRETATIVE PHENOMENOLOGICAL ANALYSIS OF 2013 BOSTON MARATHONERS' EXPERIENCE OF RUNNING A SUBSEQUENT BOSTON MARATHON}

Allison Grace

San Jose State University

Graduate Student Researcher
Theodore M. Butryn, Ph.D. San Jose State University Faculty Advisor

PURPOSE: You have been asked to participate in a research study that explores the meanings 2013 Boston Marathoners ascribe to their experience of returning to run a post-2013 Boston Marathon in the wake of the 2013 bombings. While other studies have been conducted on the 2013 Boston Marathon, little research has examined what it means to 2013 Boston Marathoners to return to the trauma site to compete.

PROCEDURE: You will complete a brief demographic questionnaire. Then, you will participate in an in-depth Skype interview about your experience of running the 2013 Boston Marathon and a post-2013 Boston Marathon. The interviews will be audio recorded by the Graduate Student Researcher and later transcribed.

POTENTIAL RISKS: The potential risks of participating in the present study are that participants may experience emotional and/or psychological discomfort during the interview process.

If you feel that you are experiencing emotional and/or psychological discomfort, please contact any of the following resources:

The Boston Public Health Commission at (617) 534-5050

The Federal Disaster Distress Helpline at 1-(800) 985-5990

The American Red Cross Disaster Mental Health Services at www.redcross.org

These hotlines offer over the phone counseling services as well as local referrals for counseling services should you wish to seek out a therapist in your area.

POTENTIAL BENEFITS: There are no explicit benefits for participants in the present study. However, this study may reveal insight into how 2013 Boston Marathon runners made sense of and interpreted their trauma experience.

COMPENSATION: Participants in this study will not be compensated.

CONFIDENTIALITY: Although the results of this study may be published, no personal, individually identifying information about you will be published. You will be referred to by a pseudonym. All interview recordings will be deleted after the final transcription. The transcripts will be kept in an encrypted folder on a password protected computer that only the Graduate Researcher will have access to. 
PARTICIPANT RIGHTS: Your participation in this study is completely voluntary. You can refuse to participate in the entire study or any part of the study without any negative effect on your relations with San Jose State University. You also have the right to skip any question you do not wish to answer. This consent form is not a contract. It is a written explanation of what will happen during the study if you decide to participate. You will not waive any rights if you choose not to participate, and there is no penalty for stopping your participation in the study.

QUESTIONS OR PROBLEMS: You are encouraged to ask questions at any time during this study.

- For further information about the study, please contact Allison Grace at bostonmarathonstudy@gmail.com or (781) 534-3524.

- Complaints about the research may be presented to Dr. Matthew Masucci, Chair of the San Jose State University Dept. of Kinesiology at matthew.masucci@ sjsu.edu or (408) 924-3021.

- For questions about participants' rights or if you feel you have been harmed in any way by your participation in this study, please contact Dr. Pamela Stacks, Associate Vice President of the Office of Research, San Jose State University, at pamela.stacks@ sjsu.edu or (408) 9242488 .

SIGNATURE: Your signature indicates that you voluntarily agree to be a part of the study, that the details of the study have been explained to you, that you have been given time to read this document, and that your questions have been answered. You will receive a copy of this consent form for your records.

Participant's Name (PRINT)

Participant's Signature

Date

\section{CONSENT TO AUDIO/VIDEO RECORDING:}

- By checking the box on the left and printing and signing my name, I voluntarily agree to participate in an interview that will be conducted Skype video conferencing software.

Participant's Name (PRINT)

Participant's Signature

Date

- By checking the box on the left and printing and signing my name, I voluntarily agree to have my interview audio recorded for transcription and analysis by the Graduate Student Researcher.

Participant's Name (PRINT)

Participant's Signature

Date

RESEARCHER STATEMENT: I certify that the participant has been given adequate time to learn about the study and ask questions. It is my opinion that the participant understands his/her rights and the purpose, risks, benefits, and procedures of the research and has voluntarily agreed to participate. 


\section{APPENDIX E \\ INTERVIEW GUIDE}

1. Please tell me about the lead up to the 2013 Boston Marathon for you.

a. What did it mean for you to run Boston?

2. Tell me about your race that day, walk me through that day for you.

a. At what point did you learn what had happened, what was that like for you?

3. When they stopped the race, what was that like?

a. Tell me about what was happening around you?

b. Who was with you, what were you/they saying?

4. Afterwards, when you learned what had happened/were watching the news, etc., tell me what that was like for you?

a. When you were able to let it sink in/process what had happened, what was it like knowing you had been there? That you had experienced that directly?

b. Tell me more about that/what was that like for you?

5. Walk me through the process of making the decision to run the Boston Marathon again?

a. Can you tell me about what influenced your decision to come back?

b. What were your feelings/emotions once you decided you wanted to come back (to run Boston)?

c. How did you feel when you were training?

6. So, race day comes and you're back, what was that day like for you?

a. Tell me what it was like for you to be at the same location you were at in 2013, when you had first heard something was wrong?

b. What was that like for you?

7. Can you talk to me about what it was like for you to cross the finish line?

a. Tell me more about that, what were you feeling in that moment?

b. Later that day, maybe that evening, what were you feeling? Tell me how that day was different for you from 2013.

8. Is there anything that we did not have a chance to speak about today related to your experiences at Boston that you feel would be important for me to know/for us to discuss before we conclude the interview? 


\section{APPENDIX F}

THEME TABLE

\begin{tabular}{|c|c|}
\hline Raw Data Theme & Theme \\
\hline $\begin{array}{l}\text { Non-runner } \rightarrow \text { runner } \\
\text { Teammate } \\
\text { Marathoner }\end{array}$ & Running identity \\
\hline $\begin{array}{l}\text { History, legacy of event } \\
\text { Favorite race } \\
\text { Civic pride in city } \\
\text { Large crowds } \\
\text { Most prestigious of the "big" U.S. marathons } \\
\text { Boston Marathon is prestigious } \\
\text { Lots of spectators } \\
\text { Crowd energy } \\
\text { Party atmosphere } \\
\text { Welcoming atmosphere }\end{array}$ & Boston Marathon is a unique race experience \\
\hline $\begin{array}{l}\text { Confused } \\
\text { Shocked } \\
\text { Disruption } \\
\text { Chaos } \\
\text { Cannon } \\
\text { Fireworks } \\
\text { Accident } \\
\text { "Turn around" } \\
\text { No information online } \\
\text { No cell phone service } \\
\text { Communication issues } \\
\end{array}$ & $\begin{array}{l}\text { Participants gaining the knowledge there had been } \\
\text { an incident at the finish line }\end{array}$ \\
\hline $\begin{array}{l}\text { Shocked } \\
\text { Disbelief } \\
\text { Anxiety } \\
\text { Can't process } \\
\text { No emotion } \\
\text { Felt like spectator }\end{array}$ & $\begin{array}{l}\text { How participants made sense of their trauma } \\
\text { experience }\end{array}$ \\
\hline $\begin{array}{l}9 / 11 \\
\text { "That could have been me" } \\
\text { "What if?" }\end{array}$ & Identification with other terror attacks \\
\hline $\begin{array}{l}\text { Goal taken away } \\
\text { Stand up to evil } \\
\text { Not going to stop us } \\
\text { Run every year } \\
\text { Requalified } \\
\text { Resilience } \\
\text { Bigger cause } \\
\text { Stand up to attackers }\end{array}$ & $\begin{array}{l}\text { Experiencing the desire to return to the Boston } \\
\text { Marathon }\end{array}$ \\
\hline $\begin{array}{l}\text { Will it happen again? } \\
\text { Safe } \\
\text { Increased security } \\
\text { Concern } \\
\text { Not afraid }\end{array}$ & Safety/Security \\
\hline $\begin{array}{l}\text { Changed perspective } \\
\text { Not as competitive } \\
\text { Fortunate } \\
\text { Healthy } \\
\text { Gratitude } \\
\text { Ability } \\
\text { Thankful }\end{array}$ & Altered worldview \\
\hline
\end{tabular}

